\title{
Kidney and lung in pathology: mechanisms and clinical implications
}

\author{
Ersilia Satta, ${ }^{1}$ Carmelo Alfarone, ${ }^{2}$ Alfonso De Maio, ${ }^{3}$ Sandro Gentile, ${ }^{1}$ Carmine Romano, ${ }^{1}$ Mario Polverino, ${ }^{1}$ \\ Francesca Polverino 4 \\ ${ }^{1}$ Nefrocenter Research S.c.arl, Cava de' Tirreni (SA), Italy \\ ${ }^{2}$ Betadial Srl, Dialysis Center, Nefrocenter, Cava de' Tirreni (SA), Italy \\ ${ }^{3}$ CMM Srl, Dialysis Center, Nefrocenter, Cava de' Tirreni (SA), Italy \\ ${ }^{4}$ Asthma and Airway Disease Research Center, Department of Medicine, University of Arizona, Tucson, AZ, USA
}

\begin{abstract}
There is a close, physiological, relationship between kidney and lung that begin in the fetal age, and is aimed to keep homeostatic balance in the body. From a pathological point of view, the kidneys could be damaged by inflammatory mediators or by immune-mediated factors linked to a primary lung disease or, conversely, it could be the kidney disease that causes lung damage. Non-immunological mechanisms are frequently involved in renal and pulmonary diseases, as observed in chronic conditions. This crosstalk have clinical and therapeutic consequences. This review aims to describe the pulmonary-renal link in physiology and in pathological conditions.
\end{abstract}

Key words: crosstalk; acute lung injury; acute kidney injury; chemokines.

Correspondence: Prof. Mario Polverino, Nefrocenter Research S.c.arl, Via XXV Luglio 160, 84013 Cava de’ Tirreni (SA), Italy. E-mail: studiopolverino@gmail.com

Contributions: All the authors contributed equally to the study. All the authors have read and approved the final version of the manuscript.

Conflict of interest: MP and FP are members of the Editorial Board of Multidisciplinary Respiratory Medicine. The other authors declare no conflict of interest.

Ethics approval and consent to partecipate: Not applicable.

Avaibility of data and materials: Available from the corresponding author upon reasonable request. 


\section{Introduction}

Lung and kidney are intimately related from a functional standpoint, both in physiological conditions and in diseases. These interactions begin in the fetal age: in the first trimester of pregnancy, the kidney is the main source of growth factors and nutrients contributing to the maturation of the lung parenchyma, and urine is a fundamental component of the amniotic fluid, acting on pulmonary maturation and growth. From a pathological standpoint, the kidneys can be damaged by lung-derived inflammatory mediators or immune-mediated factors or viceversa. This review aims to describe the link between lung and kidney both in physiological and pathological conditions.

The body $\mathrm{pH}$ is mantained thanks to the balance between the respiratory component (carbon dioxide arterial tension: $\mathrm{PaCO}_{2}$ ) and the renal component (bicarbonates, $\mathrm{HCO}_{3}{ }^{-}$), leading to an acidbase equilibrium. A normal blood $\mathrm{pH}$ highly depends on the synergy between lung and kidney such that, if one organ is affected, the other will have to compensate in order to maintain the body $\mathrm{pH}$. Mechanical ventilation increases the renal expression of endothelial nitrogen oxide (NO) synthase [1] and stimulates the production of endothelin [2]. The lungs receive the entire cardiac output via the largest network of microcapillaries in the body. Given this crucial role, the lungs interact with many other organs such as the kidneys, liver [3], intestine [4], hind limbs [5], and pancreas [6]. The modification of partial pressure of carbon dioxide and bicarbonate concentration depends on renal and pulmonary activities. Also, the control of blood pressure and fluid homeostasis are finely controlled by the lung-kidney network through the renin-angiotensinaldosterone system (RAAS) and bradykinin pathway.

Lung and kidney are also closely related in pathological conditions. Agents released from damaged lungs can affect the kidney function and viceversa. For example, in autoimmune conditions, lungs and kidneys are often affected, such as in Wegener's granulomatosis, systemic lupus erythematosus and Goodpasture's syndrome. In other acute (acute kindey injury or acute lung injury) or chronic inflammatory conditions, such as chronic obstructive pulmonary disease (COPD), both lungs and kidneys are also affected by underlying common pathologies.

\section{Kidney and lung crosstalk in pathology}

\section{Acute kidney injury and acute lung injury}

The crosstalk between kidney and lung is evident in the critically ill patients [7]. Acute kidney injury (AKI) occurs in up to $30 \%$ of critically ill patients and is a severe clinical problem, often requiring renal replacement therapy $[8,9]$. A recent cross-sectional study of a little less than 20.000 patients found that even a modest rise in serum creatinine $(\geq 0.5 \mathrm{mg} / \mathrm{dl})$ was associated with a 6.5 -fold increase in the odds of death [10]. The increased risk of death is often derived from extrarenal complications, usually related to distant organ dysfunction, in particular the lungs, by increased permeability of congested pulmonary capillaries, as shown, since many decades ago, by a pioneering paper which coined the term "uremic lung" [11]. Acute lung injury (ALI) with hypoxemia, hypercapnia and mechanical ventilation-associated high positive end expiratory pressure (PEEP), and AKI causes an increase in mortality of up to $80 \%$ [12]. ALI worsens renal hemodynamics and function [13]. This may be in part due to the loss of the normal immune response during acute insults. ALI is a noncardiogenic pulmonary edema due to an increased alveolar flux in presence of an imbalance between (increased) epithelial permeability and (decreased) clearance of interstitial fluid, so that alveolar flooding varies with the microvascular endothelial permeability, but also with the pulmonary lymphatic drainage of interstitial fluid and with the integrity of the alveolar epithelial cell-to-cell junctions. The simultaneous presence of ALI and the most severe manifestation ARDS are the leading causes of mortality in critically ill patients.

\section{Cellular and molecular basis}

In the lung, the transvascular fluid is normally collected in the interstitium, and from there is drained by pulmonary lymphatics. The integrity of alveolar epithelial barrier is crucial in preventing alveolar flooding by interstitial fluid. Furthermore, alveolar fluid is removed from the distal airspaces by the active transepithelium transport of sodium and chloride channels. Both type I and type II pneumocytes express apical sodium channels and basolateral sodium potassium ATPases that actively pump sodium into the interstitium $[14,15]$. To achieve a balance between intra- and extra-cellular fluids, water is then passively drawn along the resulting osmotic gradient through aquaporin channels. Alterations in either the sodium or aquaporin channels can have profound effects on alveolar fluid balance [16-18]. More permeability leads to increases in protein and solute flux that increases oncotic pressure favoring alveolar overflowing, leading to impaired alveolar fluid clearance $[11,14,19]$. Experimental evidence suggests that pulmonary damage and edema that occur during acute kidney injury can occur even in the absence of volume overload [20]. Indeed, lung injury in the context of acute kidney injury is characterized by severe pulmonary vascular congestion, interstitial lung, focal alveolar haemorrhage and inflammatory cell infiltration [21,22]. These pulmonary effects during acute kidney injury are not limited to the endothelium, but there is also evidence of alterations in the transport of salt and water [20]. Similarly, depending on the extent of kidney damage, other organs such as the lung, can be affected. Clinical and experimental data support a direct role for AKI in the initiation and progression of ALI. When rats undergo nefrectomy, the resulting uremia rather than reperfusion is responsible for alterations in salt and water transport, that can ultimately affect the lung function. Uremic acid has been regarded as a main culprit in the common pathologies occurring in kidney and lung as a response to an acute or chronic insult affecting the kindey as primary organ. However, other cytokines and chemokines are also responsible for these common pathologies.

\section{Cytokines/chemokines}

Cytokines/chemokines play a major role in the initiation and progression of both AKI and ALI [23]. The acute loss of kidney function in mice, resulting from either ischemic AKI or bilateral nephrectomy, is associated with an increase in multiple serum cytokines/chemokines, including IL-6, IL-1 and macrophage inflammatory protein 2 . Importantly, the administration of the antiinflammatory cytokine IL-10 reduces not only circulating, but also pulmonary markers of injury and inflammation.

The induction of oxidative stress also plays an important role in the AKI-induced pulmonary dysfunction. In a rat model of rhabdomyolysis-induced oxidative stress, AKI was associated with increases in oxidative stress and inflammatory responses in the lung, with increases in lipid peroxidation and decreases in antioxidants such as reduced glutathione [7,24]. In addition, unilateral kidney ischemic/reperfusion injury in both mice and rabbits has been shown to decrease the production of superoxide dismutase, catalase and glutathione by other organs, suggesting that ischemic AKI might compromise the host response to systemic oxidative stress [25].

Conversely, intratracheal instillation of LPS has been shown to cause renal inflammation [26], suggesting that inflammatory and likely immune-mediated responses spreading from the lung cause similar pathologies in the kidney. By generating hypoxemia, 
hypercapnia and mechanical ventilation-associated high pressures, ALI could also worsen the renal hemodynamics [7]. Mechanical ventilation itself can induce and/or exacerbate ALI and contribute to harmful effects on the kidney. In the ARDS Network study comparing low tidal volume (VT) to conventional VT ventilation, protective ventilation improves mortality from ARDS and kidney function as well [27]. Mechanical ventilation can both positively and negatively affect kidney function by: i) ameliorating the body hemodynamics: ventilation improves the kidney perfusion inducing a reduction in cardiac output, redistribution of renal blood flow and stimulation of hormonal and sympathetic pathways [13]; ii) ameliorating the blood gas imbalances. Severe hypoxemia reduces renal blood flow by increasing renal vascular resistance resulting from the activation of vasoactive factors such as angiotensin II, endothelin, and a decrease in NO [28-30], that altogether induce noradrenaline release and systemic vasoconstriction [31]. In addition, low $\mathrm{PaO}_{2}$ and high $\mathrm{PaCO}_{2}$ induce apoptosis of renal tubular cells and to via derangements of kidney structure and function [32]; and ii) induce biotrauma. Biotrauma induced by mechanical ventilation is associated with the release of proinflammatory mediators into the systemic circulation. In a randomized controlled clinical study, higher levels of the cytokines TNF- $\alpha$, IL$1 \mathrm{~b}$, IL- 6 , and IL- 8 were detected in the bronchoalveolar lavage fluid and plasma of patients ventilated at conventional lung volumes compared with those treated with a lung protective strategy [33]. A follow up analysis showed that the higher VT group had higher rates of renal failure at $72 \mathrm{~h}$, and that the degree of multiorgan failure correlated with IL-6 levels [34].

\section{Kidney injury in COPD}

COPD has been described as a systemic disorder with a predominant endothelial dysfunction [35], not only in the lung but also in other organs such as the kidney. Patients with COPD frequently have microalbuminuria (MAB) that has been associated with decreased $\mathrm{PaO}_{2}$ levels. Many causes have been associated with the endothelial dysfunction in COPD. The most relevant ones are outlined below.

\section{Direct toxic effects of cigarette smoking}

Cigarette smoking (CS) components (including nicotine and its metabolites) directly induce apoptosis of epithelial cells in vitro, and components of CS (acrolein, superoxide anion, and hydroxyl radicals) that are potentially harmful for the kidney have been detected in the circulation [36-39]. Inhaling CS increases the permeability of the alveolar-capillary barrier, and this likely enables CS components to enter the circulation and directly injure epithelial cells in the pulmonary and systemic circulations.

\section{Auto-antibodies}

Circulating anti-antibodies directed against epithelial cells [40] have been detected in COPD patients. CS-induced direct injury to epithelial cells may lead to the generation of neo-epitopes that trigger an immune response in susceptible individuals. This immune response is associated with the generation of anti-endothelial antibodies that form immune complexes with their cognate antigens on epithelial cells, thus contributing to organ (and kidney) tissue dysfunction, injury, and inflammatory responses [40].

\section{Vascular inflammation}

Systemic inflammation occurring in COPD patients may contribute to the development of both pulmonary [41] and systemic [42] endothelial dysfunction thereby contributing to the development of emphysema, pulmonary arterial hypertension, and chronic renal injury in COPD patients. Due to the release of CS-induced inflammatory cytokines and chemokines, epithelial cells are activated in the pulmonary vessels of COPD patients, and secrete inducible adhesion molecules (E- and P-selectin, and intercellular adhesion molecule-1) [43]. These adhesion and inflammatory molecules, in turn, induce a status of inflammation and increased intravascular coagulation in the kidney.

\section{Oxidative stress}

Increased oxidative stress, which increases the generation of lipid peroxidation products $[44,45]$, plays a key role in the pathogenesis of COPD [46]. CS contains large numbers of reactive oxygen species (ROS) and reactive nitrogen species (RNS). ROS and RNS are generated by circulating inflammatory cells activated by CS. Activation of epithelial cells by oxidative stress is associated with intravascular micro-thrombosis, reduced blood flow, and further activation of inflammatory cells to release ROS and RNS in the kidney $[47,48]$. Another factor contributing to COPD-associated kidney injury is the Nuclear erythroid Related Factor-2 (NRF2). NRF2 is a transcription factor which responds to oxidative stress by binding to anti-oxidant response elements in the nucleus to promote the transcription of many antioxidants and cyto-protective genes [49]. NRF2 is one of the most important anti-oxidant pathways in the lung, and protects the endothelium from oxidantinduced injury that occurs during aging, diabetes mellitus, and hypertension [50]. Decreases in NRF2 have been associated with increses oxidative processes both in lung and kidney.

\section{AGES-RAGE pathway}

Increased advanced glycation end products (AGE)- receptor for AGE (RAGE) signaling has been linked to MAB occurring in animal models of diabetes mellitus $[51,52]$. RAGE is a transmembrane receptor that is ubiquitously expressed and is activated when ligands, including AGEs, high mobility group box 1 (HMGB1), and calgranulins bind to it [53]. Signaling via RAGE increases the release of pro-inflammatory mediators by activating transcription factors including NF-kB, leading to tissue inflammation and injury [53]. Recently, oxidative stress-induced increased RAGE signaling was linked to endothelial injury in the lungs and kidneys of human COPD patients and CS-exposed mice [54]. In a recent study, Polverino et al. assessed pathologic and ultrastructural renal lesions, and measured urinary albumin/creatinine ratios, tissue oxidative stress levels, and AGEs and RAGE levels in pulmonary and renal endothelial cells from COPD patients and controls who all underwent renal biopsy or nephrectomy, and from CS-exposed mice. They found that patients with COPD and/or CS-exposed mice had chronic renal injury (higher percentage of sclerotic glomeruli and more global glomerulosclerosis and tubulointerstitial fibrosis), increased urinary albumin/creatinine ratios, and increased tissue oxidative stress and AGEs-RAGE levels in pulmonary and renal endothelial cells [54] vs controls. Increased AGE-RAGE levels were associated with endothelial dyfunction, inflammation, and oxidative stress in both lung and kidney in a preclinical model of COPD and in COPD patients [54]. Importantly, the endothelial dysfuntion was observed only in COPD patients and not in smokers without COPD, hinting at the fact that the presence of COPD, and not of CS by itself, is mainly associated with endothelial dysfunction in lung and kidney.

\section{Vasoactive mediators}

Nitric oxide: Nitric oxide (NO) is a gaseous molecule which is produced by endothelial cells and other cells. NO reduces vascular smooth muscle tone, inhibits smooth muscle proliferation and migration, and platelet aggregation, promotes endothelial cell homeostasis, and suppresses the release of inflammatory mediators from endothelial cells [55]. There are three isoforms of NO: neuronal, inducible and endothelial (eNOS), with the latter being the main responsible for production of NO by endothelial cells [5658]. Decreases in production or exchange of NO occur in response 
to CS in different compartments of the airways. In turn, deficient NO levels can induce insufficient blood flow to the kidney and vasoconstriction inducing kidney failure [59].

Prostacyclin: Prostacyclin is synthesized by prostacyclin synthase and is released, along with NO, by epithelial cells [60]. Prostacyclin induces vasodilation, and inhibits platelet aggregation and mitogenesis of various cells [61]. Reduced prostacyclin expression by endothelial cells has been linked to endothelial dysfunction in COPD. Pulmonary endothelial cells in COPD patients have lower prostacyclin synthase levels than cells in lungs from control participants $[62,64]$. CS-driven reduced expression of prostacyclin by endothelial cells contributes to endothelial dysfunction in both the systemic and pulmonary circulations of COPD patients, thus promoting emphysema development, pulmonary arterial hypertension, and other COPD co-morbidities.

Endothelin-1: The endothelium releases mediators with deleterious activities on vessels including endothelin-1 [61]. Endothelins are peptides with vasoconstrictor activities. There are three endothelin isoforms (endothelin-1, -2, and -3) [65]. Endothelin-1 is the predominant isoform in the vasculature and the most potent known vasoconstrictor. CS-induced endothelin-1 increases induce vascular dysfunction in several organs including kidney, via endothelin-1 potent vasoconstrictor, pro-inflammatory and mitogenic activities, and induces the release of free radicals froms and platelet activation [66]. Mice lacking endothelin-1 are protected from chronic renal injury and MAB in models of diabetes mellitus and renal ischemia-reperfusion injury [67,68]. Also, transgenic mice over-expressing human endothelin-1 develop age-related glomerulosclerosis and interstitial fibrosis associated with increased renal endothelial cell apoptosis [69].

Renin-angiotensin-aldosterone system (RAAS): Angiotensin-II is a vaso-active mediator that potently stimulates vasoconstriction in the systemic and pulmonary circulations, and has pro-inflammatory and profibrotic activities [70]. Angiotensin II is generated by angiotensin-converting enzyme-1 (ACE-I) which is highly expressed by pulmonary endothelial cellss and its expression increases during chronic hypoxia. Surprisingly the pulmonary and kidney levels of both ACE-I and Angiotensin II are reduced in mice in response to CS [35], and their decrease is associated with increases in the AGE-RAGE pathway, inflammation and oxidative stress in both organs. Interestingly, patients with COPD frequently have microalbuminuria (MAB) that has been associated with decreased $\mathrm{PaO}_{2}$ levels.

\section{Clinical and therapeutic implications}

The link between kidney and lung has to be kept in mind in the daily clinical practice. Approximately $24 \%$ of patients with COPD (vs $4 \%$ of control subjects) have persistent microalbuminuria $[71,72]$. Microalbuminuria is frequent in patients with COPD and is associated with hypoxemia independent of other cardiovascular risk factors [59]. Moreover, estimated glomerular filtration rate (eGFR) is directly correlated with the $\mathrm{FEV}_{1 \%}$ predicted. Subjects with repetitive renal endothelial injury [54] had significantly lower $\mathrm{FEV}_{1 \%}$ predicted values and lower eGFRs than patients with lesser endothelial injury [54]. Thus, in the clinical practice, it is important to evaluate kidney function in patients with (especially chronic) pulmonary diseases and viceversa.

Based on the tight links between kidney and lung both in pathology and physiology, drugs typically used for the treatment of systemic hypertension and diabetes, such as enalapril and metformin, have been tested in chronic lung diseases such as COPD $[35,73]$. Treating mice with enalapril attenuated CS-induced increases in urinary albumin/creatinine ratios, tissue oxidative stress levels, endothelial cell AGEs and RAGE levels, pulmonary and renal cell apoptosis, and the progression of chronic renal and pulmonary lesions [35]. Thus, it is feasible that microalbuminuria could be used as a biomarker to identify a subset of patients with COPD in whom angiotensin-converting enzyme inhibitor therapy may improve renal and lung function by reducing endothelial injury. In another study [73], mice were exposed chronically to CS and fed metformin-enriched chow for the second half of exposure. Metformin protected against CS-induced pulmonary inflammation and airspace enlargement; small airway remodeling, glomerular shrinkage, oxidative stress, apoptosis, telomere damage, aging and dysmetabolism in vivo and in vitro. Moreover, the authors evaluated the association of metformin use with indices of emphysema progression over 5 years of follow up among the COPDGene (Genetic Epidemiology of COPD) study participants [74]. Within COPDGene, participants receiving metformin compared with those not receiving it had a slower progression of emphysema and a slower adjusted lung density decrease.

These studies provide an indirect evidence of the kidney-lung link and point towards clinical trials testing the efficacy of drugs currently used for disease other than COPD, in limiting COPD and/or emphysema progression and its systemic consequences.

\section{Conclusions}

The close relationship between lung and kidney is evidence of a homeostatic connection between all organs and systems in an attempt to maintain the body system balance. Lung and kidney are main players in the effort to maintain such balance in both physiological and pathological conditions. It is necessary to search for the clinical signs of a disease not only in the primary affected organ but also in other organs that are functionally related. In the era of precision medicine, we should move towards the identification of common pathologies underlying a disease (endotypes) and affecting several organ system in order to treat not only the symptoms, but the underlying systemic pathologies in a selected subset of well-characterized patients.

\section{References}

1. Choi WI, Quinn DA, Park KM, Moufarrej RK, Jafari B, Syrkina O, et al. Systemic microvascular leak in an in vivo rat model of ventilator-induced lung injury. Am J Respir Crit Care Med 2003; 167:1627-32.

2. Kuiper JW, Versteilen AM, Niessen HW, Vaschetto RR, Sipkema P, Heijnen CJ, et al. Production of endothelin-1 and reduced blood flow in the rat kidney during lung-injurious mechanical ventilation. Anesth Analg 2008;107:1276-83.

3. Colletti LM, Kunkel SL, Walz A, Burdick MD, Kunkel RG, Wilke CA, et al. Chemokine expression during hepatic ischemia/reperfusion-induced lung injury in the rat. The role of epithelial neutrophil activating protein. J Clin Invest 1995;95:134-41.

4. Kadesky KM, Turnage RH, Rogers TE, Inman L, Myers SI. In vitro evidence of neutrophil-mediated lung injury after intestinal reperfusion. Shock 1995;4:102-6.

5. Welbourn R, Goldman G, O'Riordain M, Lindsay TF, Paterson IS, Kobzik L, et al. Role for tumor necrosis factor as mediator of lung injury following lower torso ischemia. J Appl Physiol (1985) 1991;70:2645-9.

6. Yang J, Murphy C, Denham W, Botchkina G, Tracey KJ, Norman J. Evidence of a central role for p38 map kinase induction of tumor necrosis factor alpha in pancreatitis-associated 
pulmonary injury. Surgery 1999;126:216-22.

7. Ko GJ, Rabb H, Hassoun HT. Kidney-lung crosstalk in the critically ill patient. Blood Purif 2009;28:75-83.

8. Star RA. Treatment of acute renal failure. Kidney Int 1998;54:1817-31.

9. Uchino S, Kellum JA, Bellomo R, Doig GS, Morimatsu H, Morgera S, et al. Acute renal failure in critically ill patients: a multinational, multicenter study. JAMA 2005;294:813-8.

10. Chertow GM, Burdick E, Honour M, Bonventre JV, Bates DW. Acute kidney injury, mortality, length of stay, and costs in hospitalized patients. J Am Soc Nephrol 2005;16:3365-70.

11. Bass HE, Singer E. Pulmonary changes in uremia. J Am Med Assoc 1950;144:819-23.

12. Mehta RL, Pascual MT, Gruta CG, Zhuang S, Chertow GM. Refining predictive models in critically ill patients with acute renal failure. J Am Soc Nephrol 2002;13:1350-7.

13. Kuiper JW, Groeneveld AB, Slutsky AS, Plötz FB. Mechanical ventilation and acute renal failure. Crit Care Med 2005;33:1408-15.

14. Matthay MA, Folkesson HG, Clerici C. Lung epithelial fluid transport and the resolution of pulmonary edema. Physiol Rev 2002;82:569-600.

15. Folkesson HG, Matthay MA. Alveolar epithelial ion and fluid transport: recent progress. Am J Respir Cell Mol Biol 2006;35:10-9.

16. Matthay MA, Folkesson HG, Verkman AS. Salt and water transport across alveolar and distal airway epithelia in the adult lung. Am J Physiol 1996;270:L487-503.

17. Dematte JE, Sznajder JI. Mechanisms of pulmonary edema clearance: from basic research to clinical implication. Intensive Care Med 2000;26:477-80.

18. Verkman AS, Matthay MA, Song Y. Aquaporin water channels and lung physiology. Am J Physiol Lung Cell Mol Physio. 2000;278:L867-79.

19. Matthay MA, Zimmerman GA, Esmon C, Bhattacharya J, Coller B, Doerschuk CM, et al. Future research directions in acute lung injury: summary of a National Heart, Lung, and Blood Institute working group. Am J Respir Crit Care Med 2003; $167: 1027-35$.

20. Rabb H, Wang Z, Nemoto T, Hotchkiss J, Yokota N, Soleimani M. Acute renal failure leads to dysregulation of lung salt and water channels. Kidney Int 2003;63:600-6.

21. Kramer AA, Postler G, Salhab KF, Mendez C, Carey LC, Rabb $\mathrm{H}$. Renal ischemia/reperfusion leads to macrophage-mediated increase in pulmonary vascular permeability. Kidney Int 1999;55:2362-7.

22. Hassoun HT, Grigoryev DN, Lie ML, Liu M, Cheadle C, Tuder $\mathrm{RM}$, et al. Ischemic acute kidney injury induces a distant organ functional and genomic response distinguishable from bilateral nephrectomy. Am J Physiol Renal Physiol 2007;293:F30-40.

23. Molls RR, Savransky V, Liu M, Bevans S, Mehta T, Tuder RM, et al. Keratinocyte-derived chemokine is an early biomarker of ischemic acute kidney injury. Am J Physiol Renal Physiol 2006;290:F1187-93.

24. Rodrigo R, Trujillo S, Bosco C. Biochemical and ultrastructural lung damage induced by rhabdomyolysis in the rat. Exp Biol Med (Maywood) 2006;231:1430-8.

25. Yildirim A, Gumus M, Dalga S, Sahin YN, Akcay F. Dehydroepiandrosterone improves hepatic antioxidant systems after renal ischemia-reperfusion injury in rabbits. Ann Clin Lab Sci 2003;33:459-64.

26. Peng X, Hassoun PM, Sammani S, McVerry BJ, Burne MJ, Rabb H, et al. Protective effects of sphingosine 1-phosphate in murine endotoxin-induced inflammatory lung injury. Am J Respir Crit Care Med 2004;169:1245-51.

27. Valenza F, Sibilla S, Porro GA, Brambilla A, Tredici S,
Nicolini G, et al. An improved in vivo rat model for the study of mechanical ventilatory support effects on organs distal to the lung. Crit Care Med 2000;28:3697-704.

28. Ballèvre L, Thonney M, Guignard JP. Role of nitric oxide in the hypoxemia-induced renal dysfunction of the newborn rabbit. Pediatr Res 1996;39:725-30.

29. Huet F, Semama DS, Gouyon JB, Guignard JP. Protective effect of perindoprilat in the hypoxemia-induced renal dysfunction in the newborn rabbit. Pediatr Res 1999;45:138-42.

30. Semama DS, Thonney M, Guignard JP. Does endothelin-1 mediate the hypoxemia-induced renal dysfunction in newborn rabbits? Biol Neonate 1995;67:216-22.

31. Anand IS, Chandrashekhar Y, Ferrari R, Sarma R, Guleria R, Jindal SK, et al. Pathogenesis of congestive state in chronic obstructive pulmonary disease. Studies of body water and sodium, renal function, hemodynamics, and plasma hormones during edema and after recovery. Circulation 1992;86:12-21.

32. Hotter G, Palacios L, Sola A. Low O2 and high CO2 in LLCPK1 cells culture mimics renal ischemia-induced apoptosis. Lab Invest 2004;84:213-20.

33. Ranieri VM, Suter PM, Tortorella C, De Tullio R, Dayer JM, Brienza A, et al. Effect of mechanical ventilation on inflammatory mediators in patients with acute respiratory distress syndrome: a randomized controlled trial. JAMA 1999;282:54-61.

34. Ranieri VM, Giunta F, Suter PM, Slutsky AS. Mechanical ventilation as a mediator of multisystem organ failure in acute respiratory distress syndrome. JAMA 2000;284:43-4.

35. Polverino F, Celli BR, Owen CA. COPD as an endothelial disorder: endothelial injury linking lesions in the lungs and other organs? (2017 Grover Conference Series). Pulm Circ 2018;8:2045894018758528.

36. Michael Pittilo R. Cigarette smoking, endothelial injury and cardiovascular disease. Int J Exp Pathol 2000;81:219-30.

37. Diken OE, Unculu S, Karnak D, Cağlayan O, Göçmen JS, Kayacan O. Cotinine levels in serum and bronchoalveolar lavage fluid. Southeast Asian J Trop Med Public Health 2010;41:1252-7.

38. Nagano T, Shimizu M, Kiyotani K, Kamataki T, Takano R, Murayama N, et al. Biomonitoring of urinary cotinine concentrations associated with plasma levels of nicotine metabolites after daily cigarette smoking in a male Japanese population. Int J Environ Res Public Health 2010;7:2953-64.

39. Shepperd CJ, Eldridge AC, Mariner DC, McEwan M, Errington G, Dixon M. A study to estimate and correlate cigarette smoke exposure in smokers in Germany as determined by filter analysis and biomarkers of exposure. Regul Toxicol Pharmacol 2009;55:97-109.

40. Taraseviciene-Stewart L, Voelkel NF. Molecular pathogenesis of emphysema. J Clin Invest 2008;118:394-402.

41. Peinado VI, Barbera JA, Ramirez J, Gomez FP, Roca J, Jover L, et al. Endothelial dysfunction in pulmonary arteries of patients with mild COPD. Am J Physiol 1998;274:L908-13.

42. Barr RG, Mesia-Vela S, Austin JH, Basner RC, Keller BM, Reeves AP, et al. Impaired flow-mediated dilation is associated with low pulmonary function and emphysema in ex-smokers: the Emphysema and Cancer Action Project (EMCAP) Study. Am J Respir Crit Care Med 2007;176:1200-7.

43. González S, Hards J, van Eeden S, Hogg JC. The expression of adhesion molecules in cigarette smoke-induced airways obstruction. Eur Respir J 1996;9:1995-2001.

44. Rahman I, van Schadewijk AA, Crowther AJ, Hiemstra PS, Stolk J, MacNee W, et al. 4-Hydroxy-2-nonenal, a specific lipid peroxidation product, is elevated in lungs of patients with chronic obstructive pulmonary disease. Am J Respir Crit Care Med 2002;166:490-5.

45. Fratta Pasini AM, Ferrari M, Stranieri C, Vallerio P, Mozzini C, 
Garbin U, et al. Nrf2 expression is increased in peripheral blood mononuclear cells derived from mild-moderate exsmoker COPD patients with persistent oxidative stress. Int J Chron Obstruct Pulmon Dis 2016;11:1733-43.

46. Owen CA. Proteinases and oxidants as targets in the treatment of chronic obstructive pulmonary disease. Proc Am Thorac Soc 2005;2:373-85; discussion 94-5.

47. Pober JS, Sessa WC. Evolving functions of endothelial cells in inflammation. Nat Rev Immunol 2007;7:803-15.

48. Cai H, Harrison DG. Endothelial dysfunction in cardiovascular diseases: the role of oxidant stress. Circ Res 2000;87:840-4.

49. Rangasamy T, Cho CY, Thimmulappa RK, Zhen L, Srisuma SS, Kensler TW, et al. Genetic ablation of Nrf2 enhances susceptibility to cigarette smoke-induced emphysema in mice. J Clin Invest 2004;114:1248-59.

50. Chen B, Lu Y, Chen Y, Cheng J. The role of Nrf2 in oxidative stress-induced endothelial injuries. $\mathrm{J}$ Endocrinol 2015;225:R83-99.

51. Gao X, Zhang H, Schmidt AM, Zhang C. AGE/RAGE produces endothelial dysfunction in coronary arterioles in type 2 diabetic mice. Am J Physiol Heart Circ Physiol 2008;295:H491-8.

52. Schmidt AM, Hori O, Cao R, Yan SD, Brett J, Wautier JL, et al. RAGE: a novel cellular receptor for advanced glycation end products. Diabetes 1996;45:S77-80.

53. Hergrueter AH, Nguyen K, Owen CA. Matrix metalloproteinases: all the RAGE in the acute respiratory distress syndrome. Am J Physiol Lung Cell Mol Physiol 2011;300:L5125.

54. Polverino F, Laucho-Contreras ME, Petersen H, Bijol V, Sholl LM, Choi ME, et al. A pilot study linking endothelial injury in lungs and kidneys in chronic obstructive pulmonary disease. Am J Respir Crit Care Med 2017;195:1464-76.

55. Hart CM. Nitric oxide in adult lung disease. Chest 1999;115:1407-17.

56. Kuhlencordt PJ, Rosel E, Gerszten RE, Morales-Ruiz M, Dombkowski D, Atkinson WJ, et al. Role of endothelial nitric oxide synthase in endothelial activation: insights from eNOS knockout endothelial cells. Am J Physiol Cell Physiol 2004;286:C1195-202.

57. Cristina de Assis M, Cristina Plotkowski M, Fierro IM, BarjaFidalgo C, de Freitas MS. Expression of inducible nitric oxide synthase in human umbilical vein endothelial cells during primary culture. Nitric Oxide 2002;7:254-61.

58. Bachetti T, Comini L, Curello S, Bastianon D, Palmieri M, Bresciani $\mathrm{G}$, et al. Co-expression and modulation of neuronal and endothelial nitric oxide synthase in human endothelial cells. J Mol Cell Cardiol 2004;37:939-45.

59. Mount PF, Power DA. Nitric oxide in the kidney: functions and regulation of synthesis. Acta Physiol (Oxf) 2006;187:43346.

60. Alhenc-Gelas F, Tsai SJ, Callahan KS, Campbell WB, Johnson AR. Stimulation of prostaglandin formation by vasoactive mediators in cultured human endothelial cells. Prostaglandins 1982;24:723-42.

61. Mitchell JA, Ali F, Bailey L, Moreno L, Harrington LS. Role of nitric oxide and prostacyclin as vasoactive hormones released by the endothelium. Exp Physiol 2008;93:141-7.

62. Nana-Sinkam SP, Lee JD, Sotto-Santiago S, Stearman RS, Keith RL, Choudhury Q, et al. Prostacyclin prevents pulmonary endothelial cell apoptosis induced by cigarette smoke. Am J Respir Crit Care Med 2007;175:676-85.

63. Lee JD, Taraseviciene-Stewart L, Keith R, Geraci MW, Voelkel NF. The expression of prostacyclin synthase is decreased in the small pulmonary arteries from patients with emphysema. Chest 2005;128:575s.

64. Nana-Sinkam SP, Lee JD, Stearman R, Sakao S, SottoSantiago S, Voelkel NF, et al. Prostacyclin synthase in smoking-related lung disease. Proc Am Thorac Soc 2006;3:517.

65. Agapitov AV, Haynes WG. Role of endothelin in cardiovascular disease. J Renin Angiotensin Aldosterone Syst 2002;3:1-15.

66. Böhm F, Pernow J. The importance of endothelin-1 for vascular dysfunction in cardiovascular disease. Cardiovasc Res.2007;76:8-18.

67. Lenoir O, Milon M, Virsolvy A, Hénique C, Schmitt A, Massé JM, et al. Direct action of endothelin-1 on podocytes promotes diabetic glomerulosclerosis. J Am Soc Nephrol 2014;25:105062.

68. Arfian N, Emoto N, Vignon-Zellweger N, Nakayama K, Yagi K, Hirata K. ET-1 deletion from endothelial cells protects the kidney during the extension phase of ischemia/reperfusion injury. Biochem Biophys Res Commun 2012;425:443-9.

69. Hocher B, Rohmeiss P, Thöne-Reineke C, Schwarz A, Burst V, van der Woude F, et al. Apoptosis in kidneys of endothelin-1 transgenic mice. J Cardiovasc Pharmacol 1998;31:S554-6.

70. Owen CA, Campbell EJ. Angiotensin II generation at the cell surface of activated neutrophils: novel cathepsin G-mediated catalytic activity that is resistant to inhibition. J Immunol 1998;160:1436-43.

71. Polatli M, Cakir A, Cildag O, Bolaman AZ, Yenisey C, Yenicerioglu Y. Microalbuminuria, von Willebrand factor and fibrinogen levels as markers of the severity in COPD exacerbation. J Thromb Thrombolysis 2008;26:97-102.

72. Casanova C, de Torres JP, Navarro J, Aguirre-Jaíme A, Toledo $\mathrm{P}$, Cordoba E, et al. Microalbuminuria and hypoxemia in patients with chronic obstructive pulmonary disease. Am J Respir Crit Care Med 2010;182:1004-10.

73. Polverino F, Wu TD, Rojas-Quintero J, Wang X, Mayo J, Tomchaney $\mathrm{M}$, et al. Metformin: Experimental and clinical evidence for a potential role in emphysema treatment. Am J Respir Crit Care Med 2021;204:651-66.

74. Regan EA, Hokanson JE, Murphy JR, Make B, Lynch DA, Beaty TH, et al. Genetic epidemiology of COPD (COPDGene) study design. COPD 2010;7:32-43.

Received for publication: 10 November 2021. Accepted for publication: 4 December 2021.

This work is licensed under a Creative Commons Attribution-NonCommercial 4.0 International License (CC BY-NC 4.0).

(C) Copyright: the Author(s), 2022

Licensee PAGEPress, Italy

Multidisciplinary Respiratory Medicine 2022; 17:819

doi:10.4081/mrm.2022.819 